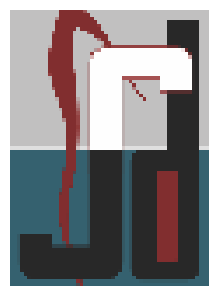

REVIEW

\title{
A Review on Prosthetic Rehabilitation of Maxillofacial Region
}

Karthikeyan.I ${ }^{1}$, Monisha Khatree ${ }^{2}$, Reetika Gaddale ${ }^{3}$, Roopa Reddy Pandraveti ${ }^{4}$

\begin{abstract}
Craniofacial region suffers from many defects due to carcinoma, trauma, iatrogenic. The treatment of facial region is compromised and complicated due to esthetics. Though surgical option is the definitive one for curing cancer, it leaves huge defects physically and depressions mentally for the patient. For a social well-being and psychological support, patients need to be addressed in a different manner. Prostheses have gained lot of support and care for patients. They complement the lost or defective tissues in the body. Well trained professionals regain internal smile for these patients in an efficient way.
\end{abstract}

Key words : Anaplastology, epithesis, Dental prostheses, Prosthetic rehabilitation

\section{INTRODUCTION:}

Anaplastology is a branch of medicine dealing with the prosthetic rehabilitation of an absent, disfigured or malformed anatomically critical location of the face or body. This term was coined by Walter.G.Spohn. An anaplastologist (also known as a maxillofacial prosthetist is an individual who has the knowledge and skill set to provide the service of customizing a facial or somato prosthesis.

Defects in the craniofacial region mostly leads to severe depression that often requires rehabilitation. ${ }^{1}$ Prostheses are artificial devices which may be implanted or attached to the body to replace an organ or body part that might be congenitally missing or might have been lost due to disease or trauma. ${ }^{2}$ Prostheses that replaces soft tissues are known as epithesis. ${ }^{3}$ Prosthetic reconstruction of a defect is complex and it depends on a factors such as size, site, etiology, severity, age, patient satisfaction and cost factor as well. ${ }^{4}$ In relation to external face or body part it may be prostheses for an eye, ear, nose, teeth or limbs. They are an illusion created to improve the standard of living of the patient. It has to be kept in mind that these tissues are not living tissues and that they cannot function as a normal organ. ${ }^{5}$ For restoration of an anopthalmic defect an ocular prostheses is made which helps the patient to cope up with the loss of the organ. Loss of an ear can be camouflaged esthetically with the help of a chemical, mechanical or surgically retained prosthesis. Nasal prostheses with good aesthetics, respiratory function and social relationship recovery is a boon to patients where surgical rehabilitation is not possible. Apart from prostheses, implants are gaining popularity, as they replace missing tooth for form and function of a patient. Dental implant is the most recent tooth replacement method that resembles the natural tooth in form, function and aesthetics. They are made up of titanium which is a bio compatible material. These implants are surgically placed in the bone and a crown is placed after a healing period of 6weeks to 6 months depending on the location of implant in the jaw. They are aesthetic, prevent bone loss and gingival recession and adjacent teeth need not be altered. They have a high success rate and immediate placement of implants is possible. This review discusses three basic prosthesis, prosthetic materials and their techniques for placement in the maxillofacial region and dental implants.

\section{MATERIALS}

In the history of anaplastology a wide range of materials have been used such as porcelain,natural rubber,gelatin and latex but the most commonly used materials are methacrylates and silicones ${ }^{6}$ Though methacrylates are durable they are relatively hard whereas silicones are flexible and soft. Pigmentation to replicate hair and skin features can be easily incorporated. It has an ability of stretching to an extent that it can become transparent at the corners and therefore blends smoothly with the surrounding skin giving an aesthetically pleasing appearance which just keeps improving with the introduction of new silicone materials. ${ }^{7}$ 


\section{RETENTION OF PROSTHESES}

Retention is a major factor for the long term success of facial prostheses. ${ }^{8}$ There are 4 methods of anchoring the prostheses. ${ }^{9}$ They are

Anatomical anchorage

Mechanical anchorage

Chemical anchorage

Surgical anchorage

Anatomical anchorage is done to already existing anatomical structures for example: an undercut area in an ocular defect. Mechanical anchorage is done with the help of spectacle frames, hair bands, magnets etc. Adhesives are used for chemical anchorage but these have the disadvantage of irritation, perspiration and movement that compromises the bond. ${ }^{10}$ The most secure type of anchorage is the surgical anchorage in which implants are most commonly used. Implants at cellular level can be retained by bio integration, fibro-osseous integration or Osseo integration. The most reliable anchorage is by Osseo integration, as the implant gets structurally and functionally integrated in to the bone. ${ }^{3}$ Principle of Osseo integration in the field of orthopaedic surgery was first introduced by Leventhal in 1951. ${ }^{11}$ Prostheses are made up of single metals or metal alloys for successful osseointgration to occur. Except gold and silver metals all other metals have the property of Osseo conduction. In metals titanium is the best choice of material for implanting prostheses. Implants made up of titanium and titanium alloys, aluminum oxide ceramics, tantalum stainless steel, cobalt and nickel based alloys shows direct contact with the bone. Advantage of titanium oxide is that they are inert, insoluble, strong to withstand functional load, resistant to body fluids and can be shaped accordingly to be placed in jaw and facial bones. Most importantly there is osteoblastic activity that predictably occurs on the titanium implant surface ${ }^{3}$ For predictable osseointegration to take place a biocompatible implant should be placed into bone with as minimally traumatic a technique as possible ${ }^{12}$.The implant should not be mobile at the time of insertion and should be extremely stable.

\section{PREPARATION OF THE PATIENT}

A surgical reconstruction is required or a prosthetic device depends on a number of factors such as age, general health, patient preference and cost. Older medically compromised patients are preferred candidates for anaplastology. Patients with poor vision. manual dexterity i.e. who are incapable to manage and maintain the prostheses are poor choices for prosthetic rehabilitation. There should be proper access to rehabilitation otherwise there would be failure of the prostheses. For a high success rate of prostheses it should be prepared on a strong foundation. Patients are to be educated about the choice of prosthesis and retentive methods to be used. They should be prepared to learn about their prostheses like about its attachment, removal and cleaning methods. They are to be educated about the limited life span of the prostheses. If the soft tissue undergo changes than a new moulage and different prostheses might be required in future.

\section{PREPARATION OF THE SITE}

Ocular : Impression of the socket is made with irreversible hydrocolloid impression material. Impression tray is fabricated from a baseplate wax by warming it over the flame and adapting it around the contours of the eye. The location of the pupil is marked and a perforation with a diameter of $3-4 \mathrm{~mm}$ is made on the baseplate wax with many perforations in the surrounding wax. ${ }^{10}$ Light body material is placed over the anatomical structure to be recorded and medium body impression material added. To stabilize the impression, before the impression sets ice cream sticks with heavy body impression material can be placed. ${ }^{13}$

\section{Nasal :}

For smaller perforations septal buttons are used since the 1970s. Prefabricated buttons are typically 2-piece units with a flexible hub and pliable discs allowing them to adapt to the curvatures of the septum. ${ }^{14}$ Blotting papers are used to soak up mucus except in the area of the perforation and determines the outline of the defect. ${ }^{15}$ The dry part is cut out to form a template. A piece of paper is placed in one nasal cavity, and the margins of the perforation are outlined from the other cavity with a cotton ball dipped in thimerosal. ${ }^{16}$ Recently 3D image of the defect is obtained by computer tomography that replicates the precise anatomy of the defect to custom fit septal buttons. ${ }^{17-20}$. Contraindications include septal deviations, absence of nasal spine, patients with active infections, patients who use intranasal drugs, and actively bleeding perforations. These cannot be placed 
in larger and irregular defects. Various impression materials are used for making impression of a nasal prostheses such as silicone ${ }^{21}$, elastomeric impression material ${ }^{22-25}$, alginate ${ }^{26}$, impression compound $^{27}$ and tissue conditioners ${ }^{23}$. The impression is used to prepare 2 molds and the prostheses is processed with silicone ${ }^{17,21,22,25,26,28,29}$ or heat cured acrylic resin. ${ }^{23,24,30-}$

${ }^{33}$ Special prostheses such as a hollow heat processed intranasal inserts ${ }^{30,31}$ or two piece conformers joined in situ by Velcro interlocking inserts ${ }^{32}$ have been used to overcome the structural deformity of the nose. Low fusing type 1 impression compound is usually applied on the medial, posterior and superior walls of the stent of each nostril and placed. Tongue blade is placed in 1 nostril to adapt the compound to the nostril of other margin and vice versa. Light body addition silicone is mixed and applied on the stent and inserted in the nostril to get a complete impression. ${ }^{34}$

\section{Auricular :}

Combination of advanced technology and digital design, color formulation and physical prostheses has enabled an excellent reciprocation of the lost organ. Specifically, the digital scanning and designing was effective in producing a perfectly mirrored shape, form, and alignment to the non-defect contralateral ear. ${ }^{35-37}$ Tray for auricular impression is made by passing the vertical reference line through superior and inferior position of the normal ear and the horizontal ala-tragus line which is extended posteriorly. Same axis is extended $7 \mathrm{~mm}$ from the periphery of the ear that marks the vertical and horizontal extent of the tray as well as decides the extent of the perauricular tissue to be covered by the trays. Appropriate size of funnel is placed on the normal ear based on the reference lines and minimum $6 \mathrm{~mm}$ of space ensured between the most distal convexity of the helix and the inner surface of the funnel. To achieve passive impression of the auricle and surrounding tissues, tissue stoppers using low fusing impression compound are fabricated which also helps in proper placement of the funnel over the soft tissue. Perforations are made in the funnel so as to retain the hydrocolloid material. Alginate is mixed with appropriate water powder ratio to a fluid mix and syringed in to the ear anatomy. Simultaneously second mix is loaded in the funnel and placed passively over the syringed material. After the setting of the material, impression is taken out with a snap movement to avoid distortion. ${ }^{38}$

Dental implant replacing missing teeth: Clear acrylic should be used to make diagnostic models in order to make accurate stent or template. A radiopaque material can be introduced in the stent at the desired site where the implant has to be placed so as to facilitate radiological scanning. Direct transfer and positioning of the implant in to the operation site is possible with the help of study casts. ${ }^{3}$ The 2 common imaging techniques used for proper placement of the prostheses are the CT and CAD-CAM technique. There are few software programs like the SimPlant 8 that guarantees ideal implant placement along with the help of the CT data. Pre-operative CT should be taken to plan the appropriate placement and size of the implant so as to evaluate the bone thickness. ${ }^{39}$ Virtual planning and rapid prototyping are gaining popularity as it helps in reducing the intra operative and postoperative complications. ${ }^{40,41} \mathrm{~A}$ custom or a stock tray is used to make the impression for the restoration after the seating of the coping on the implant is verified with a radiograph. Syringe impression material is loaded around the coping and medium or light body impression material is loaded in the tray and impression is taken. Fig 4a Radiographic image of Dental implants.

\section{DISCUSSION :}

OCULAR: patients suffering from large tumors in the head and neck region require excision with or without radiation therapy which is a standard treatment. ${ }^{42}$ The prosthodontist plays a key role in the rehabilitationof patients who have undergone radical maxillofacial surgery. Old photographs should be usedto help attain an esthetic result if no preoperative records areavailable. ${ }^{43}$ Large defects require both surgical reconstruction and a facial prosthesis to restore function and esthetics. ${ }^{44}$ To reduce the burden of the patient and for physical and psychological well-being, the replacement of facial defect and lost eye becomes the responsibility of the fellow dentist. ${ }^{45}$ The esthetics achieved at the end of the treatmentdepend on the amount of tissue removed, good contour of the inferior margin, and minimal sagging due to the weight of the prosthesis. The anatomy of the defect can be recorded accurately by rapid prototyping rather than conventional impression techniques to restore the facial prosthesis. ${ }^{46}$ The advantage of maxillofacial prostheses is that, it requires less or no 
surgery as it restores the esthetics and function in a near natural appearance. ${ }^{13}$

NASAL : A nasal septal perforation is a through-andthrough defect inany portion of the cartilaginous or bony septum with no overlying mucoperichondrium or mucoperiosteum on either side. The etiology can be infective, traumatic, iatrogenic, inflammatory, chemical, neoplastic, and systemic. 47, 48 Patient's symptoms are epistaxis, crusting, nasal obstruction, nasal discharge and headache. Large perforations lead to atrophic rhinitis and saddle nose deformity. $47,49,{ }^{50}$ Surgical options are limited and not promising (mucosal flaps and pre grafts) but the major disadvantage is breakdown at the surgical site leading to large perforation and vestibular stenosis. ${ }^{51}$ Prosthetic closure of large nasal septum has proved to be safer and more predictable. A rigid highly polished prosthesis should be designed to obturate the perforations. A onepiece extra- and intranasal impression was made.

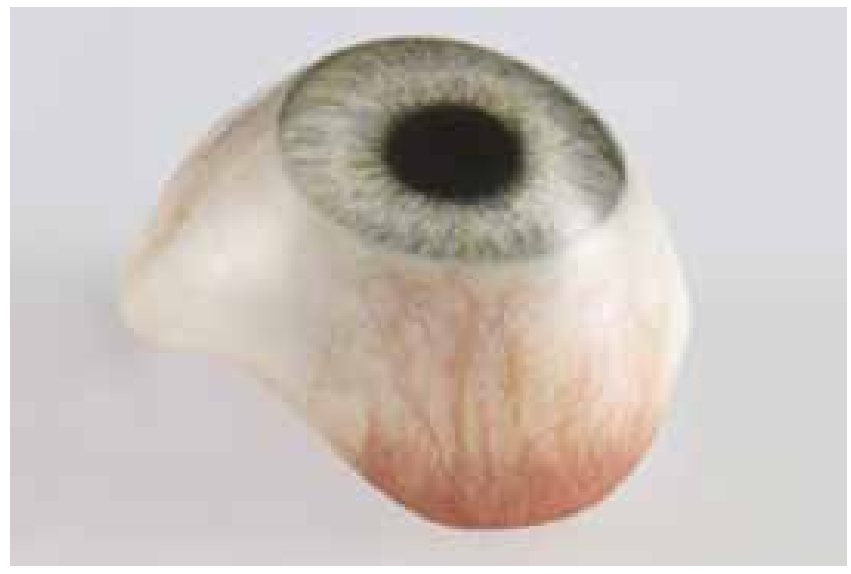

Fig: 1a Eye prosthesis

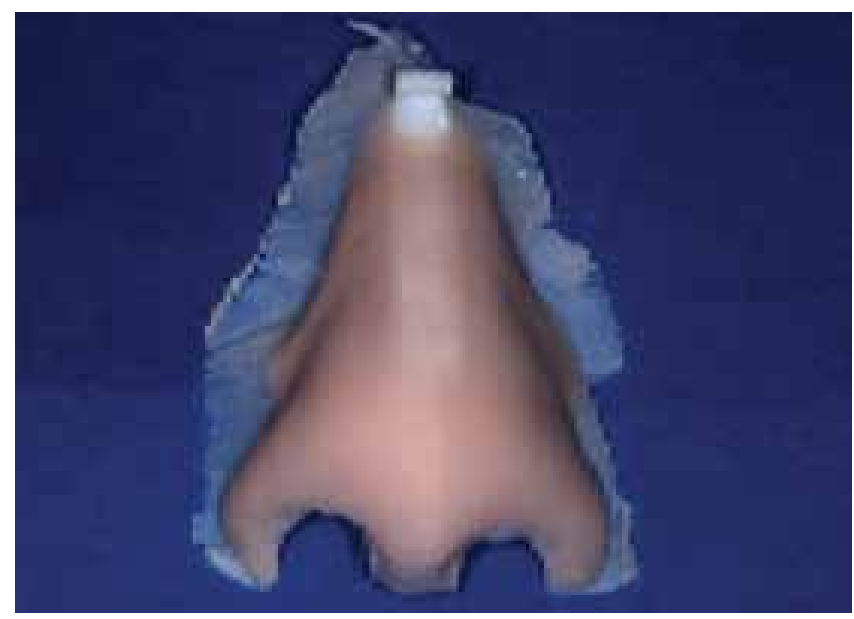

Fig: 2a Nasal Prosthesis
The obtained two intranasal impressions when joined together formed the image of one nasal defect. The extra nasal impression stabilized the intranasal impressions in their proper position, allowing the formation of an exact anatomical replica of the defect in the cast. The castwas useful in construction of an accurate prosthesis with precise positioning of magnets. These magnets were small, with strong attractive forces. They not only provided stability and retention to the prosthesis, but also helped to automatically reorient the two pieces intranasally. ${ }^{34}$

AURICULAR : Congenital or teratogenic defects leading to anamoly of pinna is termed as 'microtia'. Thorne et al showed that prosthetic reconstructionof the ear is indicated in pediatric patients with congenital deformities in cases of failed autogenous reconstruction. ${ }^{52}$ Due to surgical complications such as skin necrosis and resorption of cartilage framework prosthetic options can be considered. Prostheses to children can present challenges. The use of adhesive retention can be

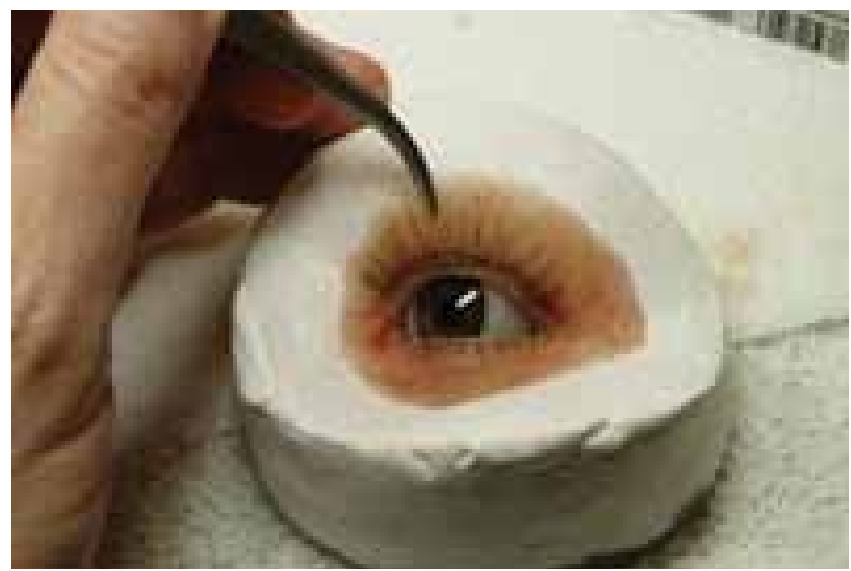

Fig: 1b Eye prosthesis fabrication

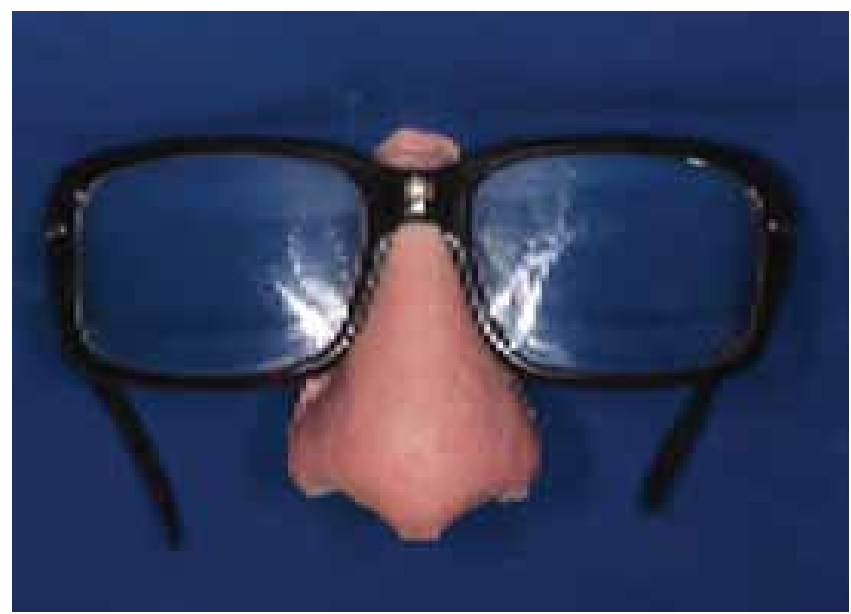

Fig: 2b Retention of Nasal Prosthesis 


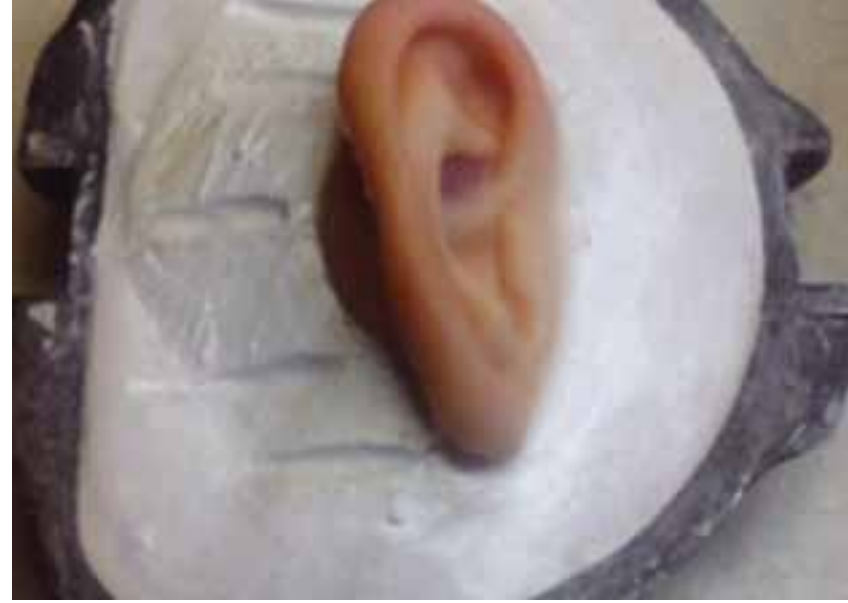

Fig: 3a Fabrication of ear prosthesis
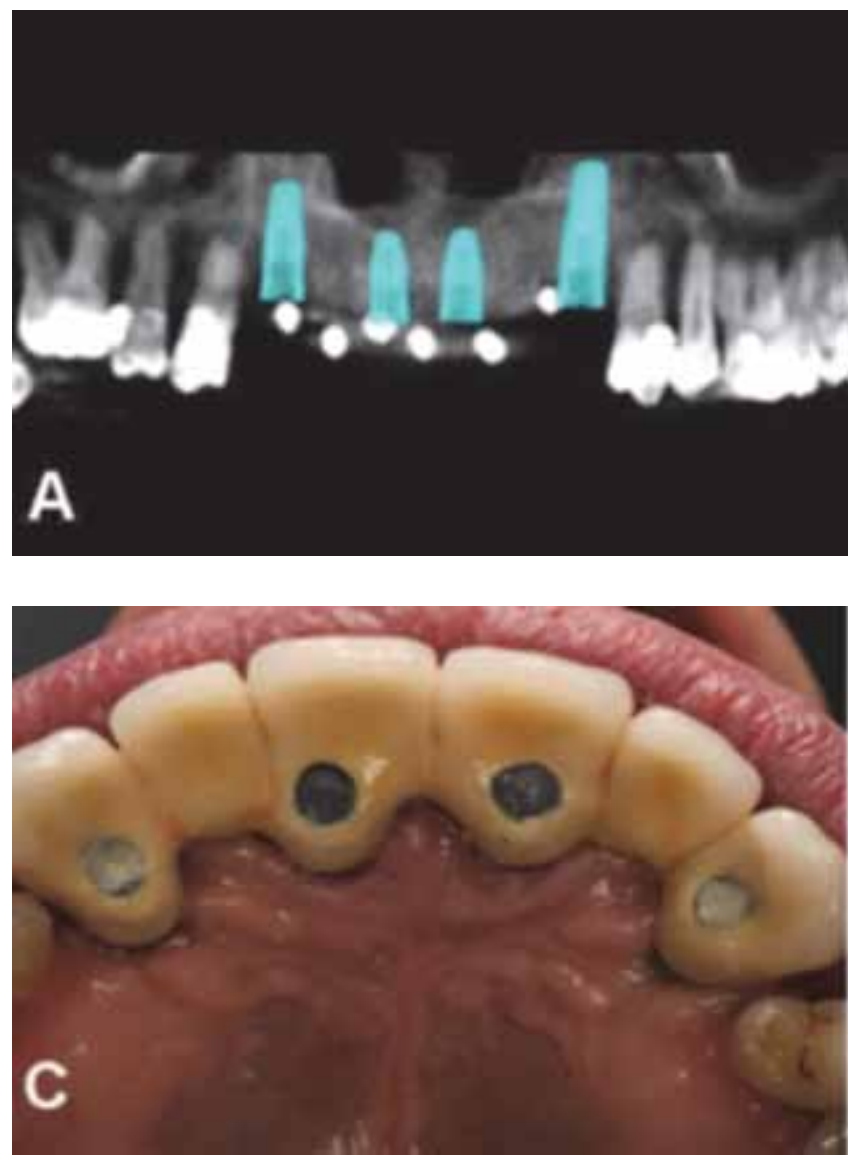

Fig 4b Clinical picture of Dental implants

problematic, as children can be very active, which can lead to loss of retention due to accidental displacement during play. Implants should always be considered the first option. The digital scanning technology saves time usually spent in waxing up and manual silicone mixing of silicone colors. As data is virtually stored and can be accessed any time by any operator, making prostheses for the same patient becomes easier without

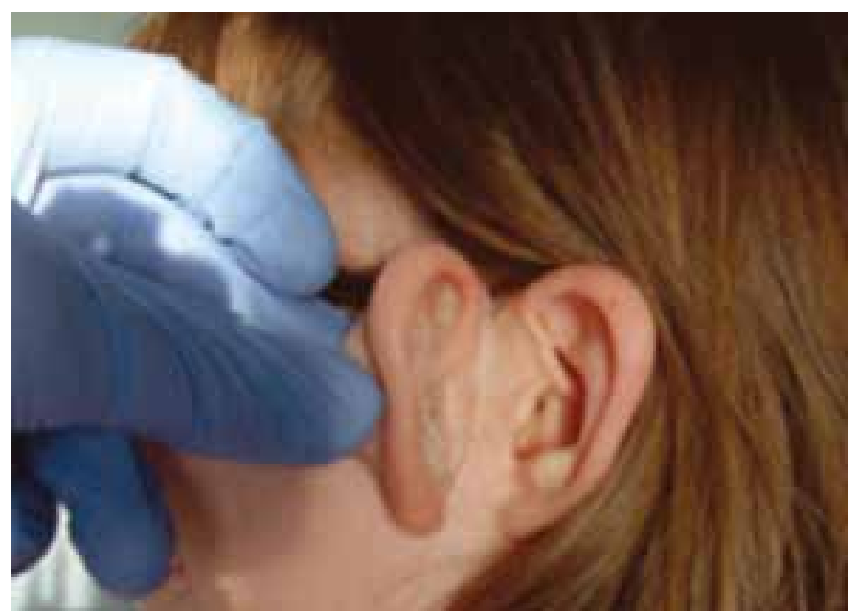

Fig: 3b Mirror image prosthesis
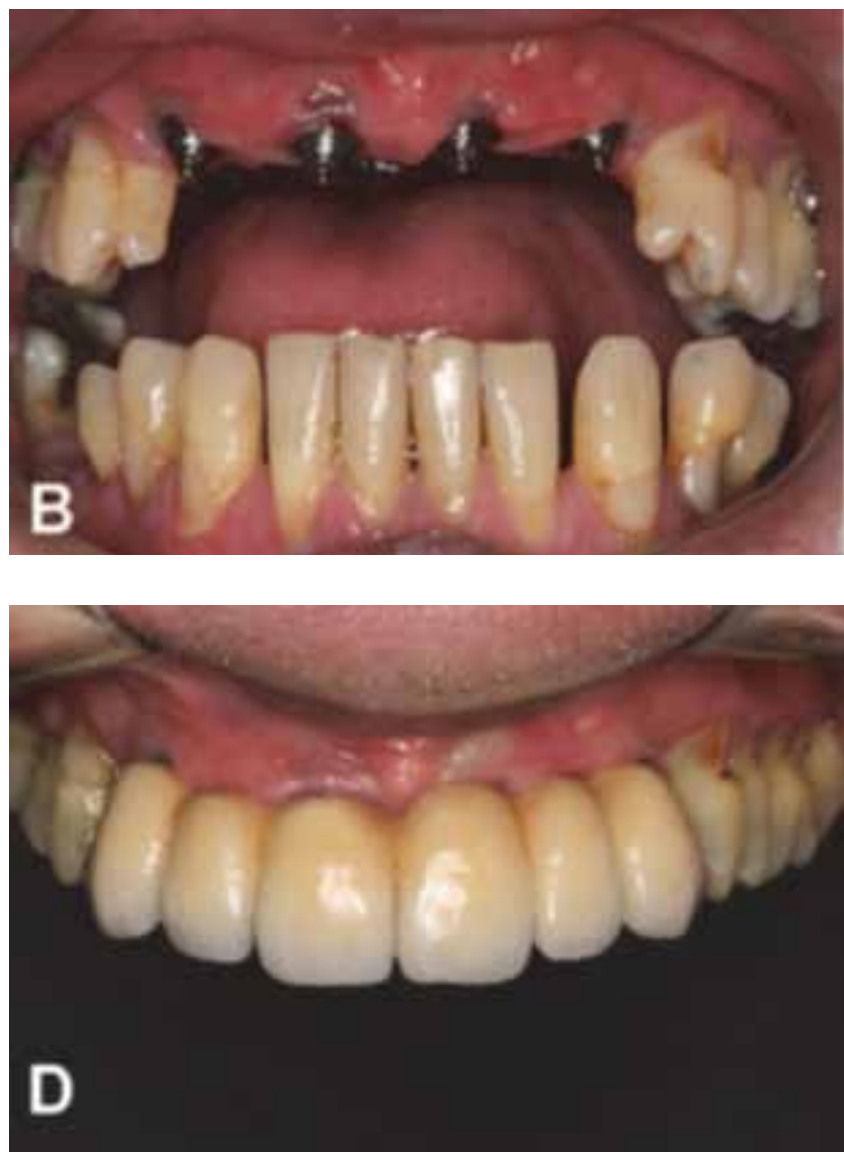

Fig 4c Palatal view of Prosthesi

the patients physical efforts. ${ }^{53}$

DENTAL IMPLANT: Implant dentistry has changed the quality of life of many patients with missing tooth and it has become more successful with the discovery of titanium. Tooth loss can be due to decay, periodontal disease, trauma, congenital, iatrogenic etc. Replacement of a missing tooth by implant compared to fixed partial 
denture is long lasting and effective. Various companies market implant but the success for placement depends on the surface characteristics, technique and the operator. Proper biomechanical loading gives long term success. Implants can be immediate or delayed regarding placement or loading. Prosthetic rehabilitation of an implant can be by acrylic, metal, metal-ceramic, zirconia etc. They replace either single tooth or a complete rehabilitation is possible.

\section{CONCLUSION:}

The prosthetic rehabilitation of patients with congenital defects, pathologies creating anomalies in facial region has significant impact on a patient's self-image and ability to function and interact socially. It brings back not only their appearance but also the confidence needed to live in the society. Even though repair is difficult, replacement is an attractive option.

\section{REFERENCE:}

1. Federspil P, Federspil PA Die epithetische Verso gung von kraniofazialenDefekten. 1998; 46: 569-578.

2. JayitaPoduval.Branemark Ear and Nose Prosthesis.Int JMed Sciences and Biotech2013; 1: 12-16

3. Dejong M, De cubber J, De Roek F, Lethaus B, Buurman $\mathrm{D}$ et al. The art of facial prosthetics.Ned Tijdschr Geneeskd 2011; 155: 39 - 67 .

4. MetinSencimen and AydinGulses. Implant Retained Auricular Prostheses, Current Concepts in Plastic Surgery, Dr. Frank Agullo (Ed.), 2012 ISBN: 978-953-51-0398-1

5. Ow RK, Amrith S.Ocular prosthetics: use of a tissue conditioner material to modify a stock ocular prosthesis. J Prosthet Dent 1997; 78: 218-22

6. Andres C. Survey of materials used in extra-oral maxillofacial prosthetics; Proceedings of Materials Research in Maxillofacial Prosthetic Academy of Dental Materials; Chicago, IL pp1992; $25-40$.

7. Federspil PA, Pauli UC, Federspil P Die Plattenepithelkarzinome der Ohrmuschel. HNO 2001; 49: 283-288.

8. Godoy AJ, Lemon JC, Nakamura SH, King GE A shade guide for acrylic resin facial prostheses. J Prosthet Dent 1992; 68: $120-122$.

9. Paschke H. Die epithetischeBehandlung von Gesichtsdefekten. München: Barth.1957

10. Prachi Thakkar, JR Patel, Rajesh Sethuraman, NarendraNirmalCustomOcular Prosthesis: A Palliative Approach. Indian J Palliat Care2012;18: 78-83.

11. Leventhal, G.S. (1951) Titanium, a metal for surgery. Journal of Bone and Joint Surgery. 1951; 33: 473

12. Branemark, P-I. Introduction to osseointegration.In: Branemark
PI, Zarb GA, Albrektson $\mathrm{T}$ (editors).Tissue-integrated prostheses. Chicago: Quintessence 1985.

13. T. V. Padmanabhan, Kasim Mohamed, Devi Parameswari, Sumathi K. NitinProsthetic Rehabilitation of an Orbital and Facial Defect: A Clinical Report.Journal of Prosthodontics. 2012;21: 200-204

14. Eliachar I, Mastros NP Improved nasal septal prosthetic button. Otolaryngol Head Neck Surg 1995; 112: 347-349

15. Janeke JB Nasal septal perforations closed with a Silastic button. S Afr Med J 1976 ;50: 2146.

16. Kern EB, Facer GW, McDonald TS, et al. Closure of nasal septal perforations with Silastic buttons-results in 45 patients. ORL Digest 1977; 39: 7-17

17. Pallanch JF, Facer GW, Kern FB, et al. Prosthetic closure of nasal septal perforations. Otolaryngol. Head Neck Surg1982; 90: $448-452$

18. Price DL, Sherris DA, Kern EB. Computed tomography for constructing custom nasal septal buttons. Arch Otolaryngol Head Neck Surg2003; 129: 1236-1239

19. Frank DA, Kern EB, Kespert DB. Measurement of large or irregular-shaped septal perforations by computed tomography. RadiolTechnol1988; 59: 409-412

20. Barraclough JP, Ellis D, Proops DW. A new method of construction of obturator for nasal septal perforations and evidence of outcomes. Clinical Otolaryngology 2007; 32: 5154

21. Gay WD. A simplified method of treating septal defects. J Prosthet Dent 1981; 45: 430-431

22. VanDishoeck EA, Lashley FO. Closure of a septal perforation by means of an obturator. Rhinology 1975; 13: 33-37

23. Zaki HS. A new approach in construction of nasal septal obturators. J Prosthet Dent 1980; 43: 654-657

24. Moergeli JR Jr. An improved obturator for a defect of the nasal septum. J Prosthet Dent 1982; 47: 419-421

25. Ginsberg NA, Van Blarcom GW. Fabrication of septalobturator prosthesis for inoperable septal perforations. Rhinology 1972; 10: $32-33$

26. Blind A, Hulterstrom A, Berggren D. Treatment of nasal septal perforations with a custom-made Prosthesis. Eur Arch Otorhinolaryngol 2009; 266: 65-69

27. Shenoy VK, Shetty P, Alva B. Pin hole nasal prosthesis: a clinical report. J Prosthet Dent 2001; 88: 359-361

28. Fruba J, Makowska W, Waloryszak B, et al. The application of the alloplastic prosthesis in the nasal septal perforations. Otolaryngol Pol 1993; 47: 58-62

29. Mullace M, Gorini E, Sbrocca M, et al. Management of nasal septal perforation using silicone nasal septal button. ActaOtorhinolaryngolItal 2006; 26: 216-218

30. Zaki HS, Myers EN. Prosthetic management of large nasal septal defects. J Prosthet Dent 1997; 77: 335-338

31. Young JM. Internal nares prosthesis. J Prosthet Dent 1970; 24: 320-323

32. Holt GR, Parel SM. Prosthetics in nasal rehabilitation. Facial 
ProsthetSurg 1984; 2: 74-84

33. McKinstry RE, Johnson JT. Acrylic nasal septal obturators for nasal septal perforations. Laryngoscope. 1989; 99:560-563

34. C.R. Sashi Purna, P.D. Annapurna, Syed Basheer Ahmed, SamyukthaVurla, et al.Two-Piece Nasal Septum Prosthesis for a Large Nasal Septum Perforation: A Clinical Report. JProsth 2013;22: 143-147

35. Turgut G, Sacak B, Kiran K, et al. Use of rapid prototyping in prosthetic auricular restoration. J CraniofacSurg 2009; 20: 321-325

36. Ciocca L, Scotti R. CAD-CAM generated ear cast by means of a laser scanner and rapid prototyping machine. J Prosthet Dent 2004; 92: 591-595

37. Subburaj K, Nair C, Rajesh S, et al. Rapid development of auricular prosthesis using $\mathrm{CAD}$ and rapid prototyping technologies. Int J Oral MaxillofacSurg2007; 36: 938-943

38. Shetty Vibha, G. N. Anandkrishna, Purwar Anupam, N. Namratha. Prefabricated Stock Trays for Impression of Auricular Region. Prefabricated Stock Trays for Impression of Auricular Region

39. Ozturk AN, Usumez A, Tosun Z. Implant-retained auricular prosthesis: a case report. Eur J Dent. 2010; 1: 71-4.

40. Almog, D. M., Benson, B. W., Wolfgang, L., Frederiksen, N. L. \& Brooks, S. L. (2006). Computerized tomography-based imaging and surgical guidance in oral implantology. J Oral Implantol: 2006; 32: 14-18.

41. Choi, J. Y., Choi, J. H., Kim, N. K., Kim, Y., Lee, J. K., Kim, M. K., Lee, J. H. \& Kim, M. J. Analysis of errors in medical rapid prototyping models. Int J Oral MaxillofacSurg, 2002;3: 23-32

42. Hecker DM, Wiens JP, Cowper TR, et al. Can we assess quality of life in patients with head and neck cancer? A preliminary report from the American Academy of Maxillofacial Prosthetics. J Prosthet Dent 2002; 88: 344-351

\section{Address of Correspondence}

Dr. Karthikeyan.I, M.D.S

Department of Periodontics \& Implantology,

Indira Gandhi Institute of Dental Science,

Mahatma Gandhi Medical college Campus,

PillaiyarKuppam, Pondicherry -607 402

Email: drikrkn@gmail.com

Tel : 9894888756
43. McClelland RC. Facial prosthesis following radical maxillofacial surgery. J Prosthet Dent 1977; 38: 327-330

44. Patil PG. Modified technique to fabricate a hollow light-weight facial prosthesis for lateral midfacial defect: a clinical report. J AdvProsthodont2010; 2: 65-70

45. Hertrampf K, Wenz HJ, Lehman KM, et al. Quality of life of patients with maxillofacial defects after treatment for malignancy. Int J Prosthodont 2004; 17: 657-665

46. Sykes LM, Parrott AM, Owen CP, et al. Applications of rapid prototyping technology in maxillofacial prosthetics. Int $\mathrm{J}$ Prosthodont2004; 17: 454-459

47. Osma U, Cureoglu S, Akbulut N, et al. The results of septal button insertion in the management of nasal septal perforation. J LaryngolOtol1999; 113: 823-824

48. Kuriloff DB. Nasal septal perforations and nasal obstruction. OtolaryngolClin N Am 1989; 22: 333-350

49. Papay FA, Eliachar I, Risica R, et al. Large septal perforations. Repair using inferior turbinate sliding advancement flap. Am J Rhinol1989; 3: 185-189

50. Davenport JC, Brain DJ, Hunt AT. Treatment of alar collapse with nasal prostheses. J Prosthet Dent 1981; 45: 435-437

51. Eng SP, Nilssen ELK, Ranta M, et al. Surgical management of septal perforation: an alternative to closure of perforation. J LaryngolOtol2001; 115: 194-197

52. Thorne $\mathrm{CH}$, Brecht LE, Bradley JP, et al. Auricular reconstruction: indications for autogenous and prosthetic techniques. PlastReconstrSurg2001; 107: 1241-1252

53. Muhanad M. Hatamleh, Jason.Construction of an ImplantRetained Auricular Prosthesis with the Aid of Contemporary Digital Technologies: A Clinical Report. J Prosthodont2013; 22: 132-136.

\section{How to cite this article :}

Karthikeyan.I, Monisha Khatree, Reetika Gaddale, Roopa Reddy Pandraveti. A Review on Prosthetic Rehabilitation of Maxillofacial Region. Journal of Scientific Dentistry, 2016;6(1):6-12

Source of Support : Nil, Conflicts of Interest : None declared

\section{Authors:}

${ }^{1}$ Senior Lecturer, Department of Periodontics \& Implantology, Indira Gandhi Institute of Dental Science, Mahatma Gandhi Medical college Campus, PillaiyarKuppam, Pondicherry.

${ }^{2}$ Dental surgeon.

${ }^{3}$ Senior Lecturer, Department Of Periodontology And Implantology. A.M.E`s Dental college, Raichur, Karnataka, India.

${ }^{4}$ Clinician 